\title{
Pelaksanaan Kampanye "\#AbsoluteMe" Bersama Into The Light Indonesia Untuk Meningkatkan Penerimaan Diri Remaja
}

\author{
Indah Deska Basanti ${ }^{1}$ \\ LSPR Communication Business and Institute, indahdeska@gmail.com \\ Achmad Adi Susanto ${ }^{2}$ \\ LSPR Communication Business and Institute, achmad.adi6@gmail.com
}

\begin{abstract}
Abstrak
Kampanye "\#AboluteMe" bertujuan untuk meningkatkan penerimaan diri pada remaja. Mengingat, munculnya beberapa fenomena di kalangan remaja, yaitu di antaranya tren Finstagram atau akun sekunder pada media sosial Instagram yang menurut Elizabeth Santoso (Psikolog) menjadi indikasi adanya dua kepribadian dan dapat berujung pada depresi (Moriand, 2018). Fenomena lainnya berupa tantangan tidak sehat di dunia maya yang diikuti oleh remaja dan tidak jarang menyakiti dirinya sendiri demi ketenaran semata. Berangkat dari fenomena tersebut, permasalahan yang dialami oleh remaja dapat dikaitkan oleh apa yang dinamakan dengan self-acceptance atau penerimaan diri. Permasalahan remaja yang hidup demi memenuhi ekspektasi lingkungan sosialnya hingga mencoba menjadi orang lain yang bukan dirinya menandakan bahwa kurangnya rasa self-acceptance dalam diri mereka. Pembuat karya berkolaborasi bersama Into The Light Indonesia dalam pembuatan kampanye yang mengangkat isu penerimaan diri di kalangan remaja ini. Kampanye "\#AbsoluteMe" menggunakan 6 langkah POSTAR menurut Goldsworthy \& Morris yang terdiri dari Positioning, Objective, Strategy, Tactics, Administration, dah Results. Hasil yang didapat dari keseluruhan insight, dapat disimpulkan bahwa kampanye ini berhasil mencapai target yang telah ditentukan yaitu jumlah pengikut melampaui 300 dan jumlah tingkat keterlibatan melampaui 1,2\%. Dari pelaksanaan kampanye ini juga didapatkan hasil, yaitu sebanyak rata-rata 83\% pengikut merasa dengan adanya konten @absoluteme_id pada Instagram dapat membuat mereka lebih puas dengan diri sendiri. Serta, dengan rata-rata 97\% pengikut akun @absoluteme_id merasa kampanye “\#AbsoluteMe" memberikan dukungan yang positif dan membantu dalam meningkatkan penerimaan diri.
\end{abstract}

Kata Kunci: Kampanye, Penerimaan Diri dan Remaja

\begin{abstract}
Abstarct
The "\#AboluteMe" campaign aims to increase self-acceptance in adolescents, given the emergence of several phenomena among adolescents, including the trend of Finstagram or second account on social media Instagram, which is an indicative of two personalities and can lead to depression according to Psychologist, Elizabeth Santoso (Moriand, 2018). Other phenomenon in the form of unhealthy challenges in cyberspace are followed by adolescents and they often hurt themselves for mere fame. Based on that phenomenon, problems experienced by adolescents can be related to what is called self-acceptance. The problems of adolescents who live to meet the expectations of their social environment to try to become someone other than
\end{abstract}


themselves indicates the lack of self-acceptance in themselves. The project designers collaborated with Into The Light Indonesia in making a campaign that raised the issue of self-acceptance among adolescents. The "\#AbsoluteMe" campaign uses 6 POSTAR steps according to Goldsworthy $\mathcal{E}$ Morris consisting of Positioning, Objective, Strategy, Tactics, Administration, and Results. The results obtained from the implementation of this campaign, namely as much as an average of $83 \%$ of Instagram followers from the \#AbsoluteMe campaign feel that having @absoluteme_id content on Instagram can make them more satisfied with themselves. Also, with an average of $97 \%$ of followers of the @absoluteme_id account, the "\#AbsoluteMe" campaign provides positive support and helps in increasing self-acceptance.

Keywords: Campaign, Self-Acceptance and Adolescents

\section{Pendahuluan}

Salah satu masa atau fase dalam kehidupan manusia adalah masa remaja. Santrock, Bapak Psikologi Remaja menyebutkan bahwa masa remaja adalah masa badai dan tekanan yaitu masa bergolak yang diwarnai oleh konflik dan perubahan suasana hati (Santrock, 2011). Berdasarkan sebuah studi pada The Journal of Early Adolescence, remaja yang mengunggah foto selfie mereka pada media sosial cenderung memiliki peningkatan kesadaran akan penampilan mereka sendiri. Remaja sering kali mencari pengakuan dalam hal penampilan fisik agar dapat diterima di masyarakat, namun kesadaran tersebut terkait dengan risiko peningkatan image tubuh yang negatif (Putri, 2018).

Belakangan ini juga muncul tantangan tidak sehat yang terjadi di dunia maya, misalnya eraser challenge (menghapus permukaan kulit dengan hapusan pensil secara cepat dan keras), choking game (mencekik leher hingga tak sadarkan diri), skip/knockout challenge (menekan bagian dada hingga tak sadarkan diri), sack tapping (memukul area kemaluan laki-laki dengan cukup keras), dan lainnya. Berbagai tantangan ini diikuti oleh para remaja dan tidak jarang hingga menyakiti diri mereka sendiri. Hal ini menunjukkan bahwa masih banyak remaja yang berani untuk membahayakan dirinya demi ketenaran semata di dunia maya (Yusuf, 2018).

Selain itu, trend untuk membuat finstagram juga sudah merajalela di kalangan para remaja. Berdasarkan definisi Urban Dictionary (Hutomo, 2018), finstagram berasal dari kata fake dan Instagram, yaitu dapat dikatakan sebagai istilah yang menggambarkan orang-orang yang membuat akun Instagram sekunder khusus untuk mengunggah gambar/foto atau video personal, yang berbeda dari citra sehari-hari akun utama. Finstagram juga biasa dikenal dengan nama second account.

Menurut Elizabeth Santoso, salah seorang psikolog di Jakarta, jika remaja membuat akun palsu untuk sebagai dua orang yang berbeda dalam menjalani kehidupannya, hal tersebut perlu diwaspadai karena dapat memberikan dampak negatif yang berujung pada depresi. Salah stau Dokter Spesialis Kesehatan Jiwa, Nova Riyant juga meneliti masalah depresi dan menyebutkan bahwa kurang lebih 941 siswa sekolah di daerah Jakarta menunjukkan lebih dari 30\% mengalami depresi dan 18,6\% di antaranya memiliki keinginan untuk bunuh diri (Moriand 2018; Azizah, 2018).

Permasalahan yang dialami oleh remaja dapat dikaitkan oleh apa yang dinamakan dengan self-acceptance atau penerimaan diri. Penerimaan diri dapat diartikan sebagai 
"Sikap yang pada dasarnya merasa puas dengan diri sendiri, kualitas-kualitas, dan bakat - bakat diri sendiri, dan pengakuan atas keterbatasan-keterbatasan diri" (Chaplin, 2011, p.451). Fenomena remaja yang hidup demi memenuhi ekspektasi lingkungan sosialnya hingga mencoba menjadi orang lain yang bukan dirinya menandakan bahwa kurangnya rasa self-acceptance dalam diri mereka. Pentingnya penerimaan diri di kalangan remaja dapat dilakukan melalui komunikasi, salah satunya dalam bentuk kampanye.

Kampanye "\#AbsoluteMe" yang bekerja sama dengan komunitas Into The Light Indonesia menggunakan media sosial sebagai media utama, karena dari total populasi penduduk Indonesia yang berjumlah 265 juta orang, 132 juta diantaranya merupakan pengguna aktif internet, dengan $49 \%$ populasi Indonesia merupakan pengguna aktif media sosial (Hootsuite, 2018). Selain itu, Henri Kasyfi, Sekretaris Jenderal APJII, juga menyatakan bahwa $87,13 \%$ dari remaja yang menggunakan internet merupakan pengguna aktif di media sosial seperti Facebook, Instagram, Twitter dan yang lainnya (Haryanto, 2019).

Dalam menyelenggarakan kampanye "\#AbsoluteMe, pembuat karya menggunakan beberapa konsep, di antaranya konsep public relations, penerimaan diri, dan media sosial. Konsep public relations merupakan konsep yang berkaitan dengan kegiatan penciptaan pemahaman melalui pengetahuan, dan melalui kegiatan-kegiatan tersebut akan tercipta perubahan yang berdampak (Jefkins, 2004). Menurut H. Fayol (Nova, 2011), terdapat beberapa hal yang menjadi sasaran kegiatan public relations, salah satunya adalah promosi masalah kemasyarakatan, yang terdiri atas:

a) Mengkampanyekan masalah atau isu yang menyangkut kepentingan publik.

b) Mendukung kegiatan social campaign.

Berbicara tentang kampanye, Smith (2002) menyebutkan bahwa kampanye adalah seperangkat kegiatan public relations yang sistematis dengan tujuan yang spesifik, diselenggarakan dalam periode waktu tertentu, dan mengangkat isu tertentu. Dalam kaitannya dengan kampanye penerimaan diri "\#AbsoluteMe", kampanye ini termasuk ke dalam ranah public relations karena sebuah kampanye merupakan upaya yang dirancang secara terencana melalui aktivitas komunikasi serta merupakan kegiatan penciptaan pemahaman tentang pentingnya penerimaan diri remaja. Kampanye "\#AbsoluteMe" juga merupakan kampanye public relations yang direncanakan secara sistematis dalam periode waktu tertentu, mengangkat isu tertentu yaitu penerimaan diri remaja, dan bertujuan untuk meningkatkan penerimaan diri di kalangan remaja.

Penerimaan diri diartikan sebagai sebuah sikap yang pada dasarnya merasa puas dengan diri sendiri, kualitas, dan bakat diri sendiri, serta mengakui keterbatasan diri (Chaplin, 2011). Menurut Hurlock (2006), terdapat beberapa faktor yang mempengaruhi seseorang dalam penerimaan diri, yaitu sebagai berikut:

a) Pemahaman Diri

b) Harapan yang Realistis

c) Tidak Hadirnya Hambatan-Hambatan dari Lingkungan

d) Tidak Adanya Tekanan Emosi yang Berat

e) Sukses yang Sering Terjadi

f) Konsep Diri yang Stabil 
Dalam melaksanakan kampanye "\#AbsoluteMe", pembuat karya menggunakan media sosial sebagai media untuk menyampaikan pesan kampanye. Media sosial memiliki lima karakteristik utama yaitu partisipasi, keterbukaan, komunikasi, komunitas dan konektivitas. Karakteristik yang pertama adalah partisipasi, dimana dalam setiap media sosial terdapat adanya partisipasi dari pengguna (audiens) dan media itu sendiri. Karakteristik yang kedua adalah keterbukaan, dimana sebagian besar dari layanan media sosial bersifat terbuka untuk partisipasi dan umpan balik (feedback) dari audiens. Media sosial mendorong audiens untuk berpartisipasi dalam kontennya dengan berkomentar, membagikan informasi, hingga pemungutan suara. Karakteristik yang ketiga adalah adanya komunikasi yang terjadi secara dua arah atau lebih. Dalam media sosial, penyedia konten dan audiensnya dapat berkomunikasi dengan satu sama lain. Karakteristik yang keempat adalah komunitas, dimana media sosial mendukung adanya pembentukan dan pertumbuhan suatu komunitas yang berdasarkan suatu minat yang sama. Karakteristik yang terakhir adalah konektivitas, dimana sebagian besar media sosial yang ada berkembang dari adanya konektivitas dengan situs, sumber daya atau orang lain (Mayfield, 2007). Media sosial terbagi menjadi 6 kategori menurut Kaplan dan Haenlein (2010), yaitu proyek kolaborasi, blog, komunitas berbasis konten, situs jejaring sosial, dunia game virtual, dan dunia sosial virtual.

Kategori media sosial yang digunakan dalam kampanye ini adalah situs jejaring sosial (Social Networking Sites / SNS). SNS adalah situs dimana didalam situs tersebut penggunanya dapat membuat halaman web pribadi atau profil pribadi dan kemudian dapat terhubung dengan orang lain untuk berbagi konten atau berkomunikasi (Mayfield, 2007). Layanan SNS yang cukup popular adalah Instagram. Kata instagram sendiri adalah gabungan kata dari instant camera dan telegram, dimana fitur utama dari Instagram adalah untuk berbagi foto dan menuliskan komentar pada foto satu sama lain (Sengupta et al., 2012). Banyaknya fitur yang bervariasi dalam instagram membuat instagram menjadi platform yang tepat untuk melakukan kampanye "\#AbsoluteMe". Melalui fitur-fitur yang ada di instagram, komunikasi yang dilakukan oleh kampanye "\#AbsoluteMe" dapat menjadi lebih menarik dan juga efektif dengan biaya yang cenderung rendah.

Tujuan kampanye "\#AbsoluteMe" sendiri ditentukan menggunakan komponen SMART (Specific, Measureable, Achievable, Relevance, and Timed), yaitu:

- Specific

Kampanye "\#AbsoluteMe" memiliki tujuan yang spesifik, yaitu untuk meningkatkan penerimaan diri di kalangan remaja. Tujuan yang spesifik dibuat agar fokus dalam kampanye ini terarah dan tidak bercabang.

- Measurable

Tujuan karya harus memenuhi aspek measureable atau dapat dikur. Pengukuran keberhasilan kampanye "\#AbsoluteMe" menggunakan jumlah followers, insight, dan engagement di media sosial, karena media sosial adalah media utama yang digunakan dalam kampanye ini.

- Achievable 
Kampanye "\#AbsoluteMe" memiliki tujuan yang achievable atau dapat dicapai dan realistis, yaitu followers di Instagram sejumlah 300. Jumlah 300 followers diambil berdasarkan data hasil penelitian dr. Nova Riyanti Yusuf, Spkj (2018) yang menyebutkan bahwa kurang lebih 941 siswa sekolah di daerah Jakarta menunjukkan lebih dari 30\% mengalami depresi. 30\% dari 941 siswa adalah lebih dari 282 orang. Hal ini menunjukkan bahwa lebih dari 282 siswa sekolah di daerah Jakarta mengalami depresi. Oleh karena itu, berdasarkan angka tersebut pembuat karya menargetkan jumlah 300 followers, yakni mendekati angka dari data penelitian yang ada. Kemudian target lain dari kampanye ini adalah engagement rate $>1,2 \%$, yang merupakan rata-rata engagement rate di Instagram (Pepe, 2019) dan partisipan untuk \#AbsoluteJourney sebanyak 10 orang.

- Relevance

Dalam mencapai tujuan, kampanye "\#AbsoluteMe" mengangkat topik yang relevan dan belum tuntas, yaitu isu penerimaan diri di kalangan remaja. Hal ini didukung oleh data - data tentang fenomena di kalangan remaja belakangan ini.

- Timed

Kampanye "\#AbsoluteMe" memiliki timetable untuk mencapai tujuan meningkatkan penerimaan diri di kalangan remaja. Kampanye ini diselenggarakan dalam jangka waktu 2 bulan.

Kampanye "\#AbsoluteMe" memiliki manfaat untuk meningkatkan penerimaan diri pada remaja dan untuk mendorong masyarakat luas dalam menyebarkan informasi kepada kerabat mereka yang masih remaja akan pentingnya penerimaan diri.

\section{Metode}

Berdasarkan dari permasalahan penerimaan diri di kalangan remaja, pembuat karya menggunakan langkah-langkah pelaksanaan kampanye dari Simon Goldsworthy dan Trevor Morris (2011), yaitu POSTAR (Positioning, Objectives, Strategies, Tactics, Administration, Result). Langkah pertama, yaitu Positioning, dalam langkah ini pembuat karya harus menganalisis lingkungan sekitar dari perusahaan. Analisis ini bisa mengacu pada SWOT (Strength, Weakness, Opportunity, Threats). Kedua, Objectives yaitu penentuan tujuan dari kampanye yang diadakan, tujuan yang ingin dicapai mengacu pada SMART (Specific, Measurable, Achievable, Relevant \& Time-bound). Ketiga, Strategy yaitu menentukan siapa yang menjadi target dari kampanye, pesan apa yang akan disampaikan dan media apa yang akan digunakan. Keempat, Tactics yaitu menentukan taktik apa yang bisa digunakan untuk membuat sebuah kampanye berhasil. Kelima, Administration yaitu menentukan waktu dan tempat yang diperlukan, serta budget yang diperlukan. Langkah terakhir adalah Result, yaitu mengevaluasi apa saja yang telah dikerjakan, apakah kampanye berjalan dengan baik dan tujuan yang diinginkan dapat tercapai (Goldworthy \& Morris, 2011).

\section{Hasil dan Pembahasan}

Nama dari kampanye pembuat karya adalah "\#AbsoluteMe". "\#AbsoluteMe" merupakan abreviasi dari kata Absolutely Me yang berarti diri kita yang absolut, unik, spesial dan apa adanya sesuai yang telah diciptakan oleh Tuhan. Hashtag (\#) 
digunakan untuk menandakan bahwa kampanye "\#AbsoluteMe" adalah kampanye berbasis media sosial.

Pesan utama dari kampanye "\#AbsoluteMe" adalah "\#AbsoluteMe" merupakan sebuah kampanye yang bertujuan untuk meningkatkan penerimaan diri di kalangan remaja melalui media sosial. "\#AbsoluteMe" ingin mengajak para remaja untuk lebih menerima dirinya sendiri karena dengan menerima dirinya maka hal itu akan membuahkan self-love dimana akan berujung pada kepercayaan diri.

Tagline dari kampanye "\#AbsoluteMe" adalah "My Mistakes are Absolutely Me, My Scars and Body are Absolutely Me, My Imperfections are Absolutely Me. I'm \#AbsoluteMe". Tagline ini mengajak target audience untuk mau menerima semua aspek diri mereka, baik yang positif maupun negatif, karena semua aspek itulah yang membentuk diri mereka yang sekarang.

Target audience kampanye "\#AbsoluteMe" terdiri dari 2 kategori, yaitu target primer dan target sekunder. Target primer kampanye merupakan remaja berusia $15-25$ tahun, baik laki-laki maupun perempuan yang berdomisili di Jabodetabek dengan social economic status (SES) dari kelas B hingga A. Dari segi psychographic, target primer merupakan pelajar sekolah menengah dan mahasiswa yang aktif bermain media sosial, yang mana memiliki sifat kurang menerima diri apa adanya, kurang percaya diri, rendah diri, suka mengikuti dan membandingkan dirinya dengan orang lain. Sedangkan, untuk target sekunder merupakan masyarakat dengan rentan usia 26 - 45 tahun, baik laki-laki maupun perempuan, serta memiliki kerabat remaja. Target ini merupakan karyawan, wiraswasta dan ibu rumah tangga dengan SES dari kelas B hingga A yang memiliki karakteristik peduli dengan isu sekitar dan ingin membuat perubahan.

Kampanye "\#AbsoluteMe" memuat 8 jenis konten yang diunggah di Instagram selama dua bulan. Konten diunggah setiap jam 7 malam, dimana jam tersebut merupakan jam prime time Instagram. Berikut adalah konten-konten yang diunggah pada Instagram @absoluteme.id:

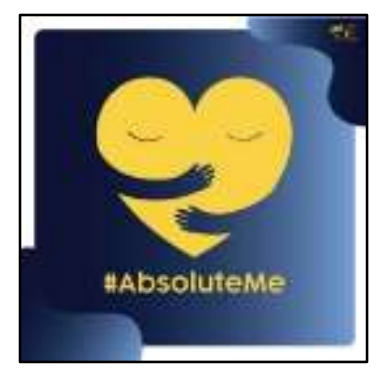

Gambar 1. Post Logo Instagram

- Logo: Logo dari kampanye "\#AbsoluteMe", sebagai post perkenalan kepada public, logo ini melambangkan seseorang yang menerima dirinya sendiri, yang disimbolkan dengan gambar hati yang memeluk dirinya sendiri. Logo akan diunggah ke Instagram dengan gaya 9-grid, dimana gambar akan dipotong menjadi 9 bagian yang sama.

- Quotes: Kutipan mengenai topik seputar penerimaan diri. Konten quotes diharapkan untuk bisa mendorong target audience yang membacanya agar dapat lebih menerima dirinya sendiri. Quotes akan diunggah dua kali seminggu, setiap hari Selasa dan Sabtu. 
- Komik: Komik pendek dengan topik sekitar penerimaan diri dengan karakter Atin Si Hati sebagai tokoh utama yang diunggah seminggu sekali setiap Rabu. Komik dibuat untuk menyajikan pesan yang ingin disampaikan dengan gaya yang lebih santai dan menarik.

- Song Recommendation: Rekomendasi lagu yang memiliki lirik dengan topik yang berhubungan dengan penerimaan diri dan diunggah seminggu sekali, setiap Kamis.

- \#AbsoluteMeMOTW atau Mission of The Week: Misi kecil yang bertujuan untuk meningkatkan penerimaan diri target audience. Mission of The Week akan diunggah seminggu sekali, setiap hari Jumat.

- \#AbsoluteJourney: Merupakan cerita dari followers mengenai pengalaman mereka dalam proses penerimaan diri. Followers akan mengunggah post dengan twibon \#AbsoluteJourney dalam Instagram pribadinya, dan setiap minggu direpost kedalam Instagram @absoluteme_id. \#AbsoluteJourney akan diunggah setiap hari Minggu.

- \#NgobrolYuk dalam Instagram Story (Snapgram): Segmen \#NgobrolYuk yang berisi tentang pertanyaan-pertanyaan singkat mengenai penerimaan diri yang akan dipost di instagram story dan followers dari @absoluteme_id bisa menjawab dengan membalas Snapgram tersebut. \#NgobrolYuk akan diunggah seminggu sekali, setiap hari Senin.

- Online Video: Kampanye "\#AbsoluteMe" akan membuat video eksperimen yang berjudul "The Compliment Game". Pesan yang ingin disampaikan dari video ini adalah agar penonton dapat lebih sering mengapresiasi diri mereka sendiri, sama seperti mudahnya mengapresiasi orang lain dalam kehidupan sehari-hari. Online video ini menggunakan 4 aktor dan 3 partisipan untuk bermain compliment game. Compliment game adalah sebuah permainan dimana partisipan akan memberikan pujian kepada partisipan yang berada di sebelahnya, secara berurutan. Setelah memuji orang lain, partisipan diminta untuk memuji bayangan mereka sendiri. Hal ini diulang sebanyak tiga kali, dengan tiga partisipan yang berbeda. Setelah permainan selesai, partisipan satu persatu akan diwawancara mengenai permainan tersebut.

Jumlah post yang diunggah oleh Instagram @absoluteme_id adalah 62 post yang terdiri dari (17 Quotes Posts, 8 Comic Posts, 9 Song Recommendation Posts, 9 \#AbsoluteMeMOTW Posts, 1 Video Experiment Post, 7 \#AbsoluteJourney Repost, 1 \#AbsoluteJourney Guide Post, Logo AbsoluteMe yang di buat menjadi 9 potongan, dan 1 Post yang berisi ucapan terimakasih bagi pengikut @absoluteme_id) dan 143 Stories.

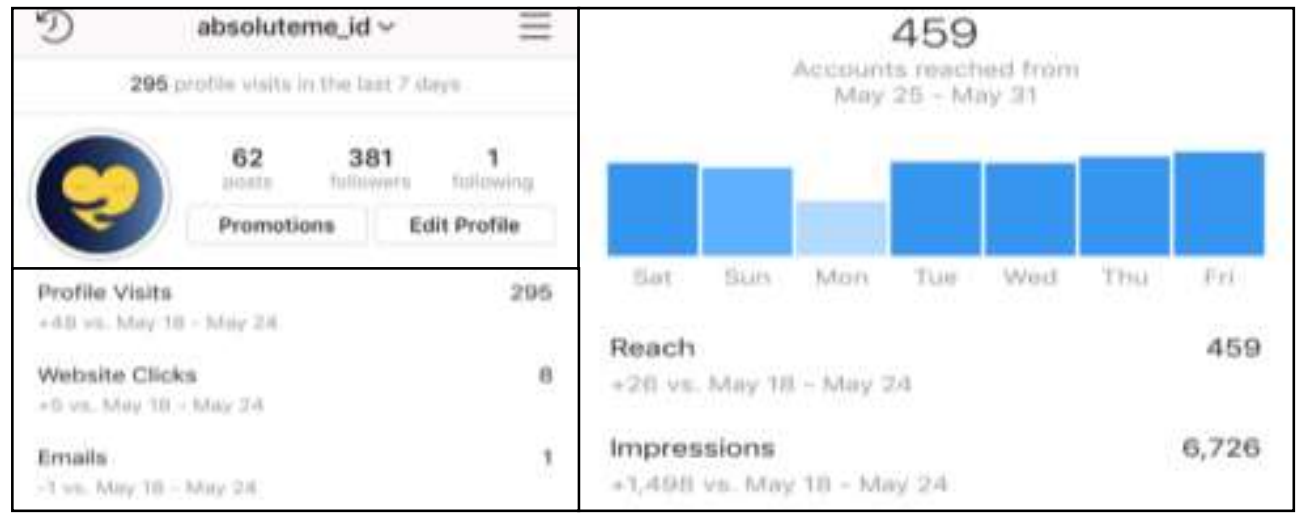

Gambar 2. Profile Insight 1 Juni 2019 
Dari profile insight jumlah insight mengalami peningkatan yang signifikan. Walaupun insight sempat mengalami penurunan, namun peningkatan kembali terjadi di minggu terakhir sampai di tanggal berakhirnya kampanye.

Untuk menganalisis content insight, pembuat karya menggunakan engagement rate. Perhitungan engagement rate berdasarkan jumlah likes dan comment dibagi dengan jumlah reach. Pada akhir masa pelaksanaan kampanye, didapatkan hasil rata - rata engagement rate dari konten quotes sebesar 15,5\%, konten komik sebesar 13,5\%, konten Mission of The Week sebesar 12\%, konten Song Recommendation sebesar 13,2\% dan konten Absolute Journey sebesar 13,4\%. Dari konten feeds Instagram yang diunggah, dapat dilihat bahwa konten quotes menunjukkan persentase yang paling tinggi, artinya paling banyak diminati oleh target audience. Dalam konten \#NgobrolYuk, yang terbagi menjadi 8 topik, yaitu Beauty Standard, Merubah Diri, Memaafkan Diri, Komentar Menyakitkan, Tantangan dalam Proses Penerimaan Diri, Role Model, Pesan Untuk Diri di Masa Lalu dan Labelling. Dari hasil analisis konten \#NgobrolYuk, topik dengan Engagement Rate paling tinggi (25,5\%) adalah \#NgobrolYuk Week 8 yang memiliki topik Labelling. Konten terakhir, yaitu Online Video, Video "The Compliment Game" telah dilihat 308 kali, dibagikan 13 kali dan disimpan oleh 3 akun yang berbeda. 61 orang menyukai video ini dan 17 orang mengkomentari video ini dengan konteks positif. Engagement rate yang didapat dari video The Compliment Game sebesar $25 \%$. Jumlah partisipan yang mengikuti \#AbsoluteJourney adalah 24 orang. Berikut adalah salah satu unggahan dari partisipan \#AbsoluteJourney.
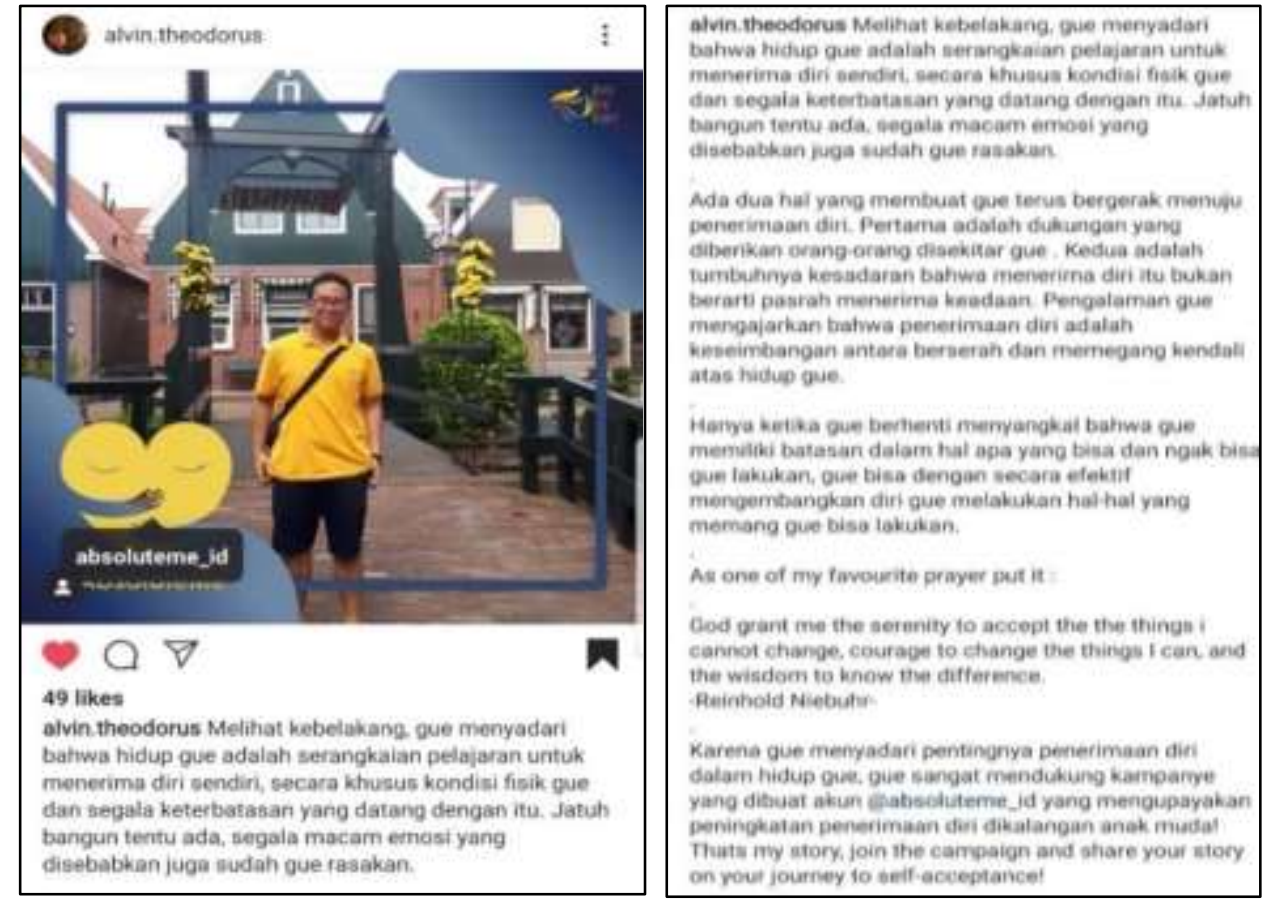

Gambar 3. Partisipan Absolute Journey

Dari keseluruhan insight, campaign ini berhasil mencapai target yang telah ditentukan yaitu jumlah followers melampaui 300, jumlah engagement rate melampaui $1,2 \%$ dan 
jumlah partisipan \#AbsoluteJourney melebihi 10 partisipan. Hal ini menunjukkan respon positif dari target audience terhadap kampanye "\#AbsoluteMe".

Pembuat karya meneliti outcome campaign dengan mengadakan polling di Instagram Story, dengan pertanyaan yang mengacu pada teori. Berikut adalah hasil dari polling.
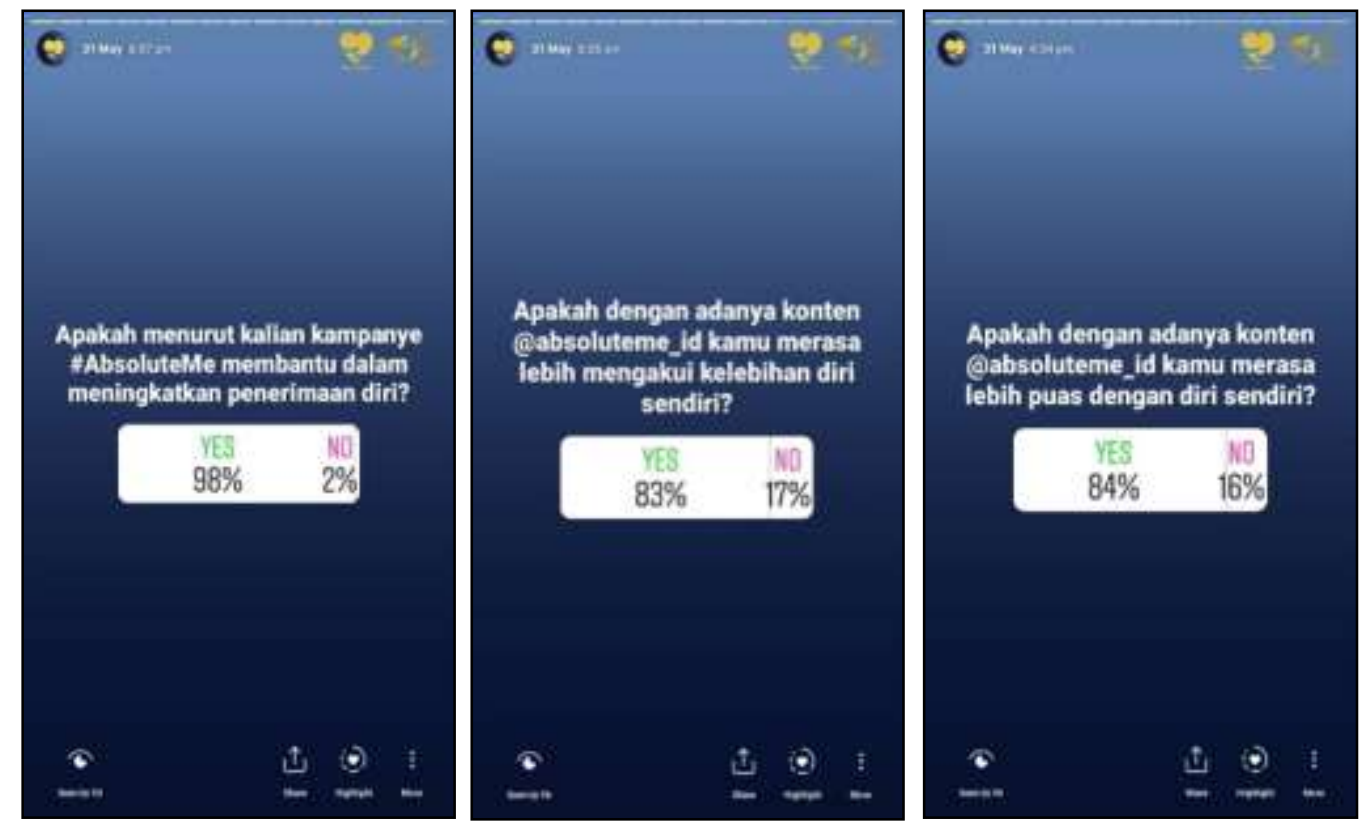

Gambar 4. Hasil Polling Instagram

Dari hasil yang didapat, sebanyak rata-rata $83 \%$ pengikut merasa dengan adanya konten @absoluteme_id dapat membuat mereka lebih puas dengan diri sendiri. Dan dengan rata-rata 97\% pengikut akun @absoluteme_id merasa kampanye "\#AbsoluteMe" memberikan dukungan yang positif dan membantu dalam meningkatkan penerimaan diri.

\section{Simpulan dan Rekomendasi}

Kampanye "\#AbsoluteMe" berhasil mencapai tujuan utama untuk meningkatkan penerimaan diri pada remaja dengan memberikan hasil dukungan yang positif dan membantu dalam meningkatkan penerimaan diri. Dengan banyaknya jumlah partisipan yang mengikuti kampanye "\#AbsoluteMe", hal ini menunjukkan bahwa para partisipan memiliki kepedulian tentang isu penerimaan diri, sudah menerima diri sendiri, atau sedang dalam proses penerimaan diri. Selain itu, para partisipan juga turut menjadi agen untuk menyebarkan isu penerimaan diri kepada para followers mereka di Instagram melalui unggahan mereka yang berisi caption tentang penerimaan diri. Karena kampanye ini merupakan kampanye media sosial, maka dari itu keberhasilan kampanye dapat diukur dari insight Instagram dengan jumlah followers melampaui 300 dan jumlah engagement rate melampaui 1,2\%. Selain itu, keberhasilan kampanye juga diukur berdasarkan polling Instagram yang menunjukan sebanyak 83\% pengikut merasa dengan adanya konten @absoluteme_id dapat membuat mereka lebih puas dengan diri sendiri dan $97 \%$ pengikut akun kampanye 
"\#AbsoluteMe" memberikan dukungan yang positif dan membantu dalam meningkatkan penerimaan diri.

Hal ini sesuai dengan definisi penerimaan diri, yaitu sikap merasa puas dengan diri sendiri, kualitas, dan bakat-bakat diri sendiri, dan mengakui keterbatasanketerbatasan diri (Chaplin, 2011). Lingkungan kampanye \# AbsoluteMe juga memberi dukungan positif yang merupakan salah satu faktor yang mempengaruhi penerimaan diri individu. Setelah melakukan strategi dan taktik kampanye yang telah dilaksanakan oleh pembuat karya, pembuat karya menyadari bahwa untuk meningkatkan penerimaan diri pada remaja yang lebih maksimal dibutuhkan strategi dan taktik yang lebih bervariasi, serta jangka waktu kampanye yang lebih lama. Inovasi yang dapat dilakukan adalah:

1. Mengadakan event mengenai penerimaan diri dalam bentuk yang bervariasi seperti seminar, workshop, talkshow dan yang lainnya.

2. Menggunakan platform media yang bervariasi seperti YouTube untuk video dan media sosial yang lainnya.

3. Bekerja sama dengan Key Opinion Leader (KOL) agar dapat menjangkau target audience yang lebih luas.

\section{Daftar Pustaka}

Azizah, K.N. (2018, Oktober 11). Riset: 30 persen remaja dki pernah depresi, sebagian sampai ingin bunuh diri. Diperoleh dari https:// health.detik.com/ beritadetikhealth/d-4251448/riset-30-persen-remaja-dki-pernah-depresi-sebagiansampai-ingin-bunuh-diri

Chaplin, J.P. (2011). Kamus lengkap psikologi (K. Kartono, Trans.). Jakarta: PT. Raja Grafindo Persada

Goldsworthy, S \& Morris, T. (2011). Pr today: the authoritative guide to public relations. London: Palgrave Macmillan

Haryanto, A.T. (2019, Mei 16). Pengguna internet Indonesia didominasi milenial. Diperoleh dari https:/ / inet.detik.com/telecommunication/d4551389/pengguna-internet-indonesia-didominasi-milenial

Hurlock, E.B (2006). Psikologi perkembangan suatu pendekatan sepanjang - rentang kehidupan (Istiwidayanti $\mathcal{E}$ Soedjarwo, Trans.). Jakarta: Erlangga

Hutomo, H. (2018, Januari 14). Finstagram makin populer di Indonesia, di sanalah terdapat keaslian dunia maya. Diperoleh dari

https://www.vice.com/id_id/article/gywme7/finstagram-makin-populer-diindonesia-di-sanalah-terdapat-keaslian-dunia-maya

Jefkins, F. (2004). Public relations (H. Munandar, Trans.). Jakarta: Erlangga

Kaplan, A. M. \& Haenlein, M. (2010). Users of the world, unite! The challenges and opportunities of social media. Business Horizons, 53, 59-68.

Mayfield, A. (2007). What is social media?. Diperoleh dari http://www.icrossing.co.uk/fileadmin/uploads/eBooks/What_is_Social_Med ia_iCrossing_ebook.pdf. iCrossing.

Moriand, A. (2018, Januari 31). Psikolog: finstagram muncul karena proses pencarian jati diri remaja. Diperoleh dari https:/ / kumparan.com/@millennial/psikologfinstagram-muncul-karena-proses-pencarian-jati-diri-remaja 
Nova, F. (2011). Crisis public relations bagaimana pr menangani krisis perusahaan. Jakarta: Raja Grafindo Persada

Pepe, G. (2019, Maret 8). 2019 instagram engagement rate benchmarks report. Diperoleh dari https:/ /jumpermedia.co/2019-instagram-engagement-rate-report/

Putri, F. I. (2018, Juli 3). Bahayanya remaja yang kecanduan selfie, dari depresi sampai bunuh diri. Diperoleh dari https:/ / health.detik.com/berita-detikhealth/d4095284/ bahayanya-remaja-yang-kecanduan-selfie-dari-depresi-sampaibunuh-diri

Santrock, J. (2011). Perkembangan anak. Edisi 7. Jakarta: Erlangga

Sengupta, S., Perlroth, N., \& Wortham, J. (2012, April 13). Instagram's success, networking the old way. Diperoleh dari https:/ / www.nytimes.com/2012/04/14/ technology/instagram-founders-were-helped-by-bay-area-connections.html

Smith, R.D. (2002). Strategic planning for public relations. Mahwah, NJ: Lawrence Erlbaum Associates

Yusuf, N. R. (2018, Juni 9). Mengulik kesehatan jiwa remaja di indonesia. Diperoleh dari https://www.idntimes.com/opinion/social/nova-riyanti-yusuf/mengulikkesehatan-jiwa-remaja-di-indonesia/ 